\section{Build confidence in research advice, says UK chief scientist}

[LONDON] Suggestions from the World Conference on Science on developing policies for science should be complemented by attention to the parallel task of building science into wider government policies, according to Sir Robert May, Britain's chief scientific adviser.

According to May, the public must have confidence in the way that science advice feeds into policy making. Policies must therefore be developed to take account of the benefits and opportunities that stem from advances in scientific knowledge, as well as caution about the potential risks.

Scientific specialists should join with others in open and wide-ranging consultations that identify, rather than exclude, particular interests and conflicts of interest, and place them in a broader perspective.

"At the same time, the fact that science, and the major issues that science and technology address, are becoming increasingly international, means that such issues need to be tackled co-operatively by all nations," says May.

May urges governments to develop their procedures for incorporating scientific advice into policy making. They should establish ways of enabling the early anticipation and identification of issues for which scientific advice or research will be needed.

Governments should be able to draw on a range of expert sources, and involve them in framing and assessing policy options. Experts from other countries or international advisory mechanisms should be involved wherever possible.

"The challenge for the Budapest conference is to focus on reaching practical proposals on these and other issues," says May. "It must not set over-ambitious objectives, while whatever emerges should be of practical value, identifying the extent and cost implications of any commitments reached."

He warns that implementing elements of the proposed draft Framework for Action could lead to the creation of "unnecessarily duplicative" follow-up groups. Given the diverse aspirations and resources of the participants, however, it is unlikely that any participant will attempt everything that is set out in the Framework, says May.

"Rather, they are likely to adopt a piecemeal approach, a bit like selecting from a menu. The task of those participating in the Budapest meeting is to ensure that this menu is both tasty and nutritious."

\title{
Readers give their hopes and fears for conference
}

[LONDON] Science ethics, environmental issues, poverty, privatization of knowledge, and bridging the knowledge gap between countries, are the priorities that readers of Nature's website would like to see addressed at next week's World Conference on Science.

But many are worried that the conference, although studded with good intentions, may not lead to practical action. The single most common concern is that the conference will be "all talk, but no action". Very few readers believe that it will result in more funds for developing countries.

Almost 300 readers of Nature's World Conference on Science web pages have already responded to a survey in which they were asked about their priorities and concerns for next week's conference in Budapest.

Asked to name the top priorities that the conference should address, a large majority of respondents listed at least one of the following: free access to knowledge; biotechnology ethics; using science to address poverty, health and environmental concerns; science education; and public access to science.

Many are concerned about the lack of adequate controls on science. But many sometimes the same respondents - hold out high hopes that science can play a leading role in reducing poverty and in tackling environmental issues such as ozone depletion, loss of forests, and climate change.

One reader from the Netherlands said he wants the conference to address: "The role of science in defining and achieving sustainable world development; and how to strike a balance between scientific freedom and the demands for certain ethical controls on what science is done and how."

Another reader, from India, said he wants the conference to address: "How science should come to terms with other knowledge systems and other civilizational systems."

Many respondents called on scientists to take more responsibility for their work and to become better public communicators. Those respondents who are scientists included in their priorities: difficulties in securing permanent jobs; insufficient funds for basic research; the need for more women scientists; and better facilities and access to science in developing countries.

Asked to name their main concern about the conference, an overwhelming majority of respondents said they feared it would be little more than a talking shop. "A wishywashy, slap-on-the-back, aren't we great affair," is how one reader fears the conference might turn out. "One's main worry is that it is a lot of hot air leading nowhere," remarked another reader, from Australia.

Some believe the conference is dominated by government-appointed delegates, and should have included more representatives of young people and non-governmental organizations, from all countries.

"I would like to participate, even paying myself, but was told that a special invitation is required. Who can give me one?" asks one reader from Italy. A reader from the United States expresses concern that "It will be simply a gathering of the 'usual suspects', speaking politely and guardedly, rather than facing crucial issues squarely and speaking frankly."

But one reader from Belgium is a little more optimistic: "I think it is a very good starting point to think about science and its impact on society. The risk is that there will be no concrete actions, only nice intentions." Full text: http://helix.nature.com/wos/a47.htm

\section{Wature brings daily news from Budapest}

Nature's news writers will be providing daily electronic coverage of the World Conference on Science from Saturday 26 June, the first day of the meeting, up to Friday 2 July, the day after the closing session.

Material will include news items on the main speeches delivered to the conference, reports on discussions about the texts of the Declaration and Framework for Action that are due to be adopted on the final day of the conference, and interviews with key participants.

A questionnaire that includes the

Æ๑) 1999 Macmillan Magazines Ltd opportunity for readers to submit their hopes and fears for the conference (see above) remains open on the website, which can be reached either through the Nature home page (http://www.nature.com) or direct on http://helix.nature.com/wcs.

All respondents to the questionnaire will be eligible to receive a free supplement that Nature will be producing after the conference. This will include reports on the meeting and its conclusions, as well as selected opinion articles on the topics under discussion in Budapest that have appeared on the website. 